\title{
The role of ICTs in the revival of cultural heritage in the Forum of Augustus in Rome
}

\author{
Vasiliki Geropanta \\ Università degli Studi Guglielmo Marconi. Rome, Italy \\ v.geropanta@unimarconi.it \\ Elia Margarita Cornelio-Marí \\ Universidad Juárez Autónoma de Tabasco, México \\ elia.cornelio@ujat.mx
}

Recibido: 18/7/2018 / Aceptado: 18/10/2018

doi: 10.26439/contratexto2018.n030.3148

\begin{abstract}
Aвstract. This article addresses, as a case study, the digital audiovisual projections on the Forum of Augustus in Rome, Italy, from the combined perspectives of architecture and communication. The study consists in a detailed analysis of the contextual and typological configuration of the Forum and its surrounding area. The analysis shows that the projections create new hybrid spaces that emerge from the deployment of a digital layer on the physical space of the archeological site. Following the theory of conservation/ restoration, we argue that, through this instance of augmented reality, the meaning and value of the area become apparent. The new emerging heterotopic space has effects on the visitors to the Forum but also on the passersby that can observe the monumental projections from the surrounding streets.
\end{abstract}

Keywords: ICTs / cultural heritage / smart cities / restoration / conservation 


\section{El rol de las TIC en el renacimiento de la herencia cultural en el Foro de Augusto en Roma}

RESUMEN. Este artículo utiliza, como caso de estudio, las proyecciones
audiovisuales digitales en el Foro de Augusto en Roma, Italia, desde la
perspectiva conjunta de la arquitectura y la comunicación. El estudio consiste
en un análisis detallado de la configuración contextual y tipológica del foro y
de su área circundante. El análisis muestra que las proyecciones crean nuevos
espacios que emergen de la aplicación de una capa digital en el espacio físico
del sitio arqueológico. Siguiendo la teoría de la conservación/restauración,
sostenemos que, a través de este ejemplo de realidad aumentada, el significado
y el valor del área se hacen evidentes. El nuevo espacio heterotópico que surge
tiene un efecto en los visitantes del foro, pero también en los transeúntes que
pueden observar las proyecciones monumentales desde las calles aledañas.
Palabras clave: TIC / herencia cultural / ciudades inteligentes / restauración /
conservación 


\section{Introduction}

$\mathrm{T}$ he fourth industrial revolution, built on the basis of the third revolution of digitization, "is characterized by a fusion of technologies that is blurring the lines between the physical, digital, and biological spheres" (Schwab, 2016, paragraph 2). The velocity, scope and impact it will have on the systems of production, management and governance are already being felt in many sectors of human life. One of such areas of influence is the configuration of cities, with the corresponding effects on their inhabitants' daily lives.

Urban hubs are at the center of the revolution in a space brought about by the presence of Information and Communication Technologies (ICTs) as an actor (May et al, 2005). If we look at tourism, Rome is clearly one of these global hubs, being in the top 20 of the most visited cities in the world (Hedrick-Wong \& Choong, 2017). Therefore, it is a place where innovation for the sector emerges quite rapidly because it has the infrastructure and the flow of income to promote it. Also, having such a rich cultural heritage, Rome is a location to look for instances to apply ICTs in ways that are changing the use and perception of the city space. In fact, ICTs have gained presence in tourism due to their ability to interconnect commercial objectives with practical approaches for the revival of cultural heritage in the most empowering way. The ability of ICTs for creating any environment, enhanced and augmented, emerges as a response to issues of contemporary restoration and conservation, and it invokes users' recognition and interpretation of what constitutes value in an archeological site (Ronchi, 2009).

Following such premise, this article offers an examination of how this interconnection can be performed, and the way it enables changes in the public space. Specifically, it presents as a case study the projections on the Forum of Augustus, and examines the role of ICTs in the formation of new hybrid spaces that can contribute to the revival of cultural heritage sites in Rome.

\section{Description of the project}

Our general research question is: how do hybrid spaces created by the projections on the city cultural heritage contribute to the experience of urban space? A second more specific question regarding the case study is: how do the projections on the Forum of Augustus in Rome contribute to the processes of restoration/ conservation of cultural heritage in the city? The main objective is the analysis of the deployment of a layer of ICTs in an architectural landmark, extrapolating the possible effects on social practices in the district of the historical center. The applied methods are detailed analyses of the contextual and typological configuration of the Forum of Augustus and its surrounding area, complemented by a documentary research on the urban configuration of the district and the participants' observation. 


\section{The city center of Rome as a potential smart district}

Cities are organized as assemblages of landscapes. These constitute the environments in which we experience life, the places in which we act in manners that are culturally understood and shared (Barth, 2012). City landscapes may vary according to their dominant program or nature. Rome is a city that has evolved over a very long period of time and created distinctive landscapes with diverse vocations, which coincide roughly with the city's districts. Rome's city center, delimited by the ancient Aurelian Walls, is currently the setting of the Italian political power and a lively commercial district, as well as one of the main tourist destinations in the world.

It could come as a surprise to talk about Rome in an article on smart cities and the fourth industrial revolution, since this metropolis of almost three million inhabitants is rarely among the first places of smart city rankings of Italy at the European level. For instance, the 2016 Smart City Index Report places Rome in the ninth place of smartness in Italy, after the cities of Bologna, Milan, Turin, Mantua, Parma, Trento, Brescia and Reggio Emilia (EY, 2016, p. 14).

However, we would like to argue that the center of Rome shows the potential to become a smart district, partly because of the actions promoted by the tourism/heritage sector. For instance, lately there have been efforts to implement initiatives that fall into the key fields of Smart Mobility, Smart Economy and Smart Living, ${ }^{1}$ all of which impact directly on the touristic attractiveness of the city. For instance, in the key field of Smart Mobility, there are several new sharing services for automobiles (Car2Go and Enjoy), motorcycles (eCooltra) and bicycles (O'Bike). Likewise, in the key field of Smart Economy, the district shows a good standing in innovative spirit and entrepreneurship - particularly for tourism-, as well as clear international integration, aided by the opening of a new terminal at the Fiumicino Airport in 2016. Besides, the city center performs well in the indicators of the key field of Smart Living concerning cultural and leisure facilities and touristic attractiveness.

Other initiatives backed by local stakeholders confirm the idea that the city center of Rome has the potential to become a smart district. Recently, the electrical company Acea placed sensors in the area comprising the Coliseum and Via dei Fori Imperiali for monitoring traffic, security, weather, waste management, public transportation, the environment and the structural characteristics of buildings (Acea, 2017).

1 The European Smart City Model consists of six key fields: Smart Economy, Smart Mobility, Smart Environment, Smart People, Smart Living and Smart Governance (Giffinger, Kramar, Haindlmaier \& Strohmayer, 2007). 
In addition, the district has a huge presence online, due to its popularity as a tourist destination. As a result, many urban spots have virtual tours on Google Maps, and there has been local investment in the creation of augmented and virtual reality experiences for many of the tourist attractions, such as museums and archeological sites. The latest examples are the exhibition of two opulent imperial Roman villas using Augmented Reality (AR) in Palazzo Valentini, the Virtual Reality (VR) experience at the Museum of Ara Pacis called L'Ara com'era (the Ara as it was), and the projections on the Forum of Caesar and Forum of Augustus called Viaggi nell'antica Roma (journeys in ancient Rome). It is precisely this last case which has attracted our attention because of its implication for the presence of ICTs in urban heritage sites. ${ }^{2}$

\section{Hybrid spaces emerging from the projections on urban surfaces}

From a theoretical point of view, there are three components for a smart city: urban space, ICTs and skilled users (Komninos, 2014).

The presence of ICTs shows in different ways in the urban space. For instance, it can take the shape of sensors, terminals to access public information, tourist e-kiosks, displays with traffic updates, etc. It can also take the shape of a mixture of digital data and physical space, creating new smart spaces that are hybrid in nature, because they originate from the juxtaposition of a digital layer with the analogical space.

Elsewhere, we have proposed that such smart spaces are those that arise from the visual projection of digital data on existing architectural structures, such as walls or even entire buildings (Geropanta \& Cornelio-Marí, 2014). We noted then that the typical surfaces for the creation of such smart spaces were flat, even, white and aseptic. This is how they appear, for instance, in the science-fiction minimalistic imaginary of the future that we see in the movies or television. These white plain surfaces seem to be the perfect screen for projections, as if the screen of the movie theater would invade the rest of the spaces we live in. However, we have noticed that the surfaces that are already being used for some of these visual projections are rugged, colored and richly textured. This is especially true with surfaces that are part of the urban space, which in Europe is full of historical buildings. The use of this kind of urban surfaces

2 There are several examples elsewhere where ICTs have been deployed in historical sites to enhance the visitor's experience. For example, in Chania, Greece, the Yali Tzamisi mosque has been reconstructed completely in visual 3D using Structure from Motion (SfM) techniques. The result was the complete virtual revival of the monument used for digital documentation and as a tool for identifying further distortions that require structural analysis (Parthenios et al, 2015). Another example comes from Spain, where AR has been applied to enhance historical architecture in museums, archeological sites and universities (De la Fuente Prieto et al, 2017). 
for projections takes us away from the imaginary of a future where white plain surfaces would prevail, and from the idea that all smart cities should have the same minimalist outlook.

Moreover, the projections on existing urban surfaces come as some sort of backlash of the local, against the notion of the smart city as a model with the same characteristics that could be applied everywhere. In our previous work, we ventured to state that architects face a challenge in the designs to conform to the abstract, neutral and aseptic surfaces that the smart spaces would require. Instead, we find the denial of such proposition in the projections on the Imperial Fora in Rome, because in that case smart spaces originate precisely from the juxtaposition of a layer of digital data with ancient architectural surfaces that are very local in nature.

\section{The case study: visual projections on Rome's cultural heritage}

The deployment of ICTs in the urban space of Rome is changing the narratives on the past and the present of the eternal city. In particular, this can be seen in the spectacular projections that recreate the history of architectural landmarks, like the Imperial Fora, where it is possible to witness audiovisual shows that project virtual reconstructions on the existing walls, columns, and archeological remains.

Currently, there are two different spectacles, one for the Forum of Augustus and one for the Forum of
Caesar. In this article, we focus on the Forum of Augustus, which was the first one to be launched.

This spectacle was created in commemoration of the two-thousandth anniversary of Emperor Augustus's death, which took place on August 19th, 14 CE. The event was presented on April 21st, 2014, concurring with the birthday of the city of Rome. The project was originated from the initiative of two Italian renowned experts in scientific communication - Piero Angela and Paco Lanciano -, and promoted by the Municipality of Rome.

The spectacle consists in a forty-five minute audiovisual presentation made possible by the synchronization of 33 digital projectors using a web interface. The audio, narrated in Italian by Piero Angela, is available in six languages and delivered wirelessly to the audience through noise-cancelling headphones (Sistemi Integrati, 2014).

The truly spectacular visual component of the show is the fact that it is projected onto the remains of the Forum, making use of the 300-meter surface of the posterior wall, as well as the pavement and the standing columns. The resulting effect goes beyond the classical cinematographic experience, falling into the realm of what is called Augmented Reality, which in its simplest conception is defined as "the blending of reality with digital artifacts" (Klopfer, 2017, p. 52). Although we usually think that the overlay of data in AR needs the use of a device (e.g. a tablet or smartphone), this is not always 
necessary. For instance, in the case of Projection Augmented Reality, sometimes also referred to as Spatial Augmented Reality, the information is delivered in a stationary context (Bimber \& Raskar, 2005). As a result, the projections on the Forum of Augustus could be considered an instance of Augmented Reality, since they overlay on the ancient stones a layer of data that enriches their perception, creating new smart spaces in the urban environment.

These projections describe a rather multidisciplinary context; they celebrate the physical and material consistency of the place in its historic and esthetic dimension. They do so by reciting historical events that affected the architecture and materiality of the overall archeological site. The trajectory in architecture, history and culture makes up the topic of this project, while the commercial objective is the user's entertainment and education.

Visitors enter the archeological area from a fenced entrance in the southern part of Via Cavour, after passing the security control. The show suggests the participants to locate in a stable place, orientating themselves towards the thick wall on the northern part of the compound. The projections are designed to depict the history of the place from the very early construction of the Forum, narrowing down to events that affected the urban transformation of the area, until it reaches to the depiction of materials and colors that were dominant in the different phases. Computers generate light effects and a three-dimensional (3D) mapping which presents the scheme of the domes and lavish adornments, thus reconstructing historical events (e.g. fires).

The presence of ICTs mitigates the conflict that exists when representing visually elements of the trajectory that are absent in real time. Thus, ICTs act as the bridge between present time and the time in history that the creators chose to represent. In this way, the projections offer an opportunity for consciously understanding the elements presented and, therefore, preserved in the archeological site. Since history is neither static nor linear, and several events have brought up the architectural condition of today's Forum of Augustus, ICTs also help visualizing several architectural moments or several moments in which the Forum displays different forms and decorations. Then, the projections visually present architectural and cultural pieces that, when juxtaposed on the archeological site, create the illusion of the overall architectural form.

The result of this experience is interesting. Participants receive a large number of audiovisual information with a highly didactic impact. They become part of a historical moment and experience the recognition of the rich material and immaterial urban heritage of the place. Therefore, they are transformed into skilled participants that acquire knowledge and understanding of the complexity behind the current urban landscape. The physical, emotional and social experience, empowered by ICTs, reveals the existence of a heterotopic space (Foucault, 1986). 


\section{Experience of the area: novel public spaces on three scales}

The experience of the area is developed on three progressive scales. The first one includes an analysis of the archeological area, which means the public space of the Forum of Augustus, before and after the application of ICTs. We argue here that the way the artifacts change during the projections completely affects the imaginary of the archeological area. Then, we examine the relation of the Forum with its immediate surroundings, as well as the possible impact of the projections on the scale of the block. Finally, the analysis illuminates the way in which the audiovisual projections can affect the overall territory and bring about important insights for future consideration. Among these, there is what we call a spillover effect, which extends to the surrounding area. The next subsections present the novel hybrid spaces created by the application of ICTs in relation to the existing reality.

\section{The scale of the archeological area}

The Forum of Augustus is one of the five compounds that make up the Imperial Fora (the others are: Forum of Caesar, Forum of Nerva, Forum of Trajan and Forum of Vespasian), as presented in figure 1 .

Figure 1. Footprints of the Imperial Fora on the existing urban fabric. The footprint of the Forum of Augustus is highlighted in darker color

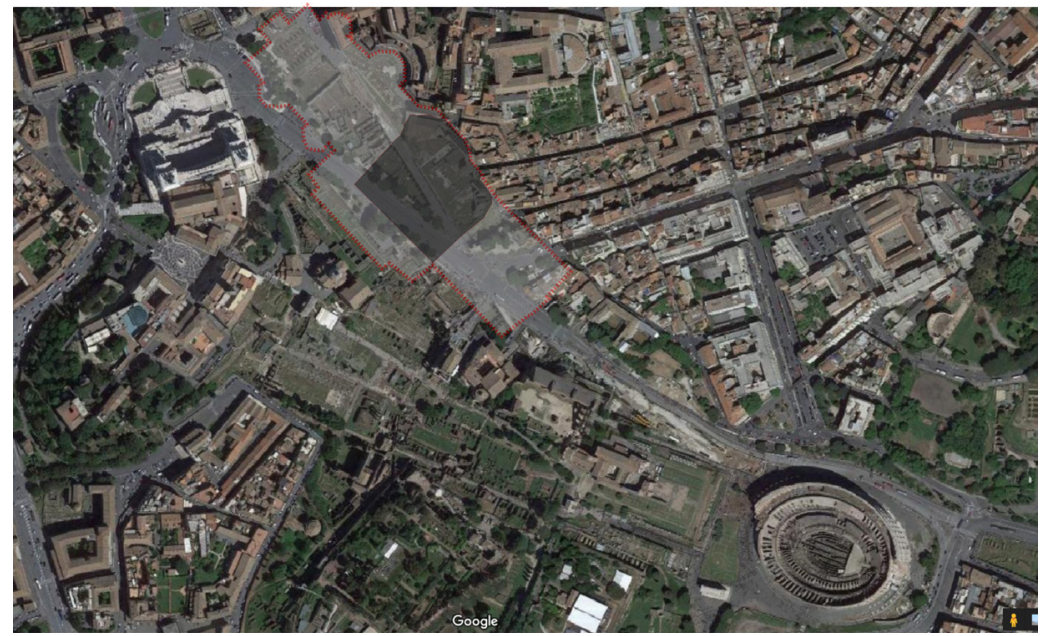

Source: Google Maps (highlight in darker color by the authors) 
As its precedents, the Forum of Augustus was a public space for civic, juridical and social activities during antiquity. Its architecture and art have been agents of ideological messages throughout history, and different political regimes have contributed in the reconstruction of its urban landscape, enriching every time the collective memory of Roman people. Although the Forum is greatly influenced by those transformations, much of its heritage is immaterial today. This is one of the main reasons that led to the creation of the audiovisual projections under analysis.
From an architectural point of view, the place initially extended between the Roman Forum and the beginning of the Subura neighborhood. It measured $120 \times$ 120 meters in total, which equal $400 \times 400$ "Roman feet", and was structured around a rectangular square of $70 \times 50$ meters. The structure leaned on the north-eastern side on a massive thick wall made by opus quadratum of blocks of peperino (a volcanic tuff) and gabine stone arranged in alternate lines in the highest point (figure 2). This formed the background of The Forum of Augustus, which aimed at separating it from the wooden shacks and frequent fires or Subura.

Figure 2. Diagrammatic analysis of the archeological site
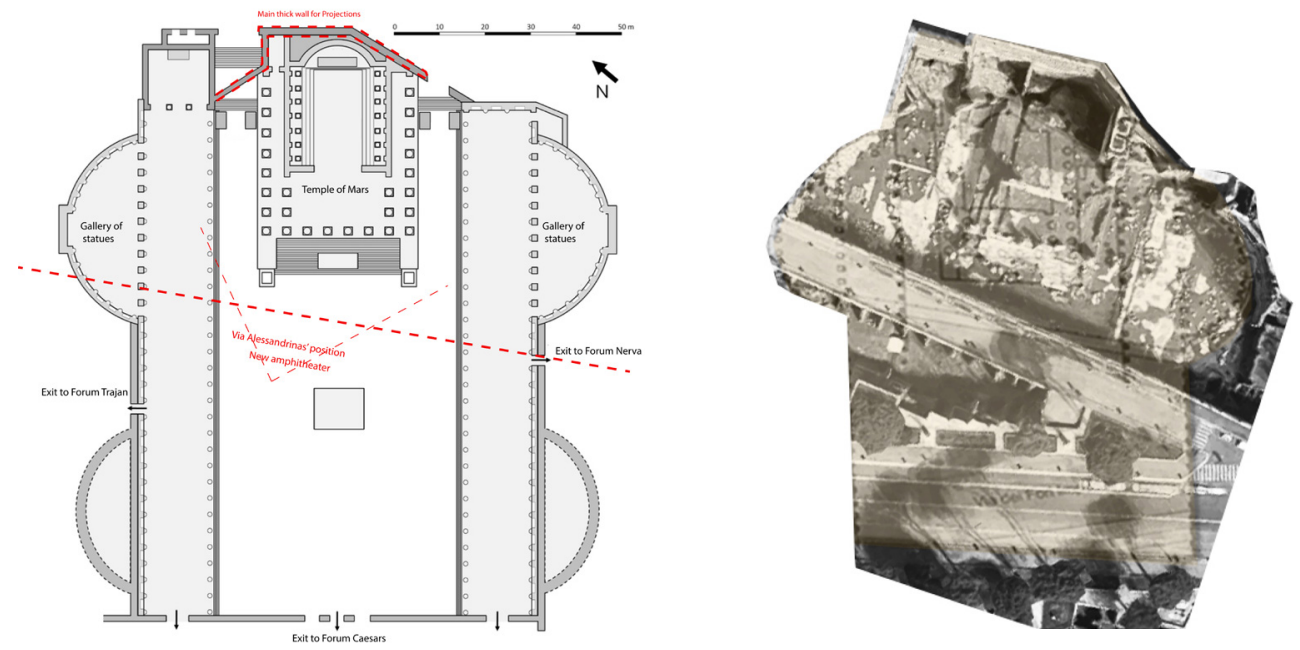

Source: elaborated by the authors 
Figure 3. Actual condition of the archeological site

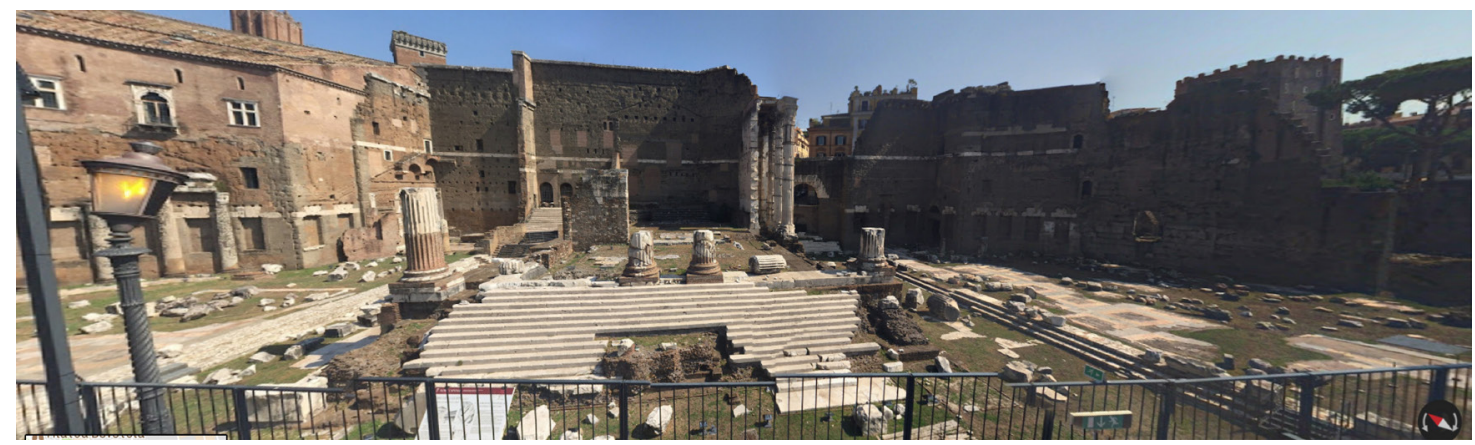

Source: Google Maps

Figure 4. 3D reconstruction of the site

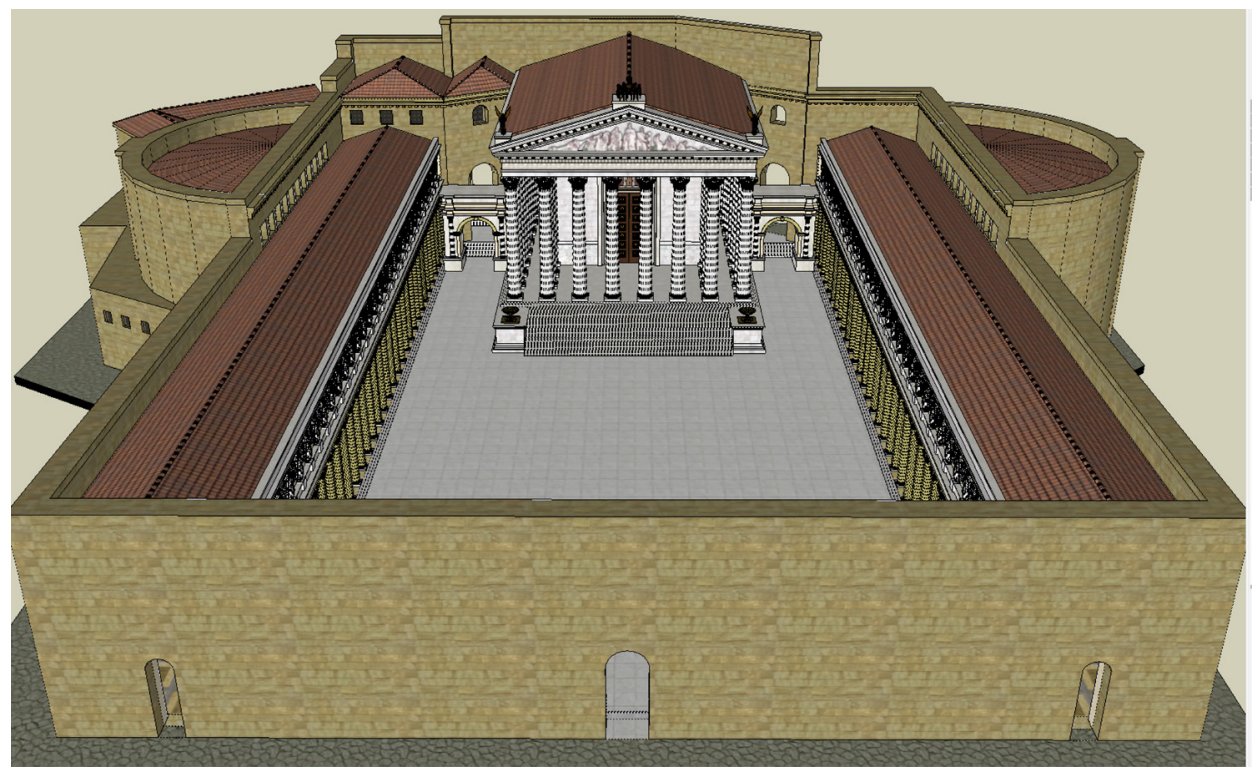

Source: elaborated by the authors 
Figure 5. Screenshot from the projections

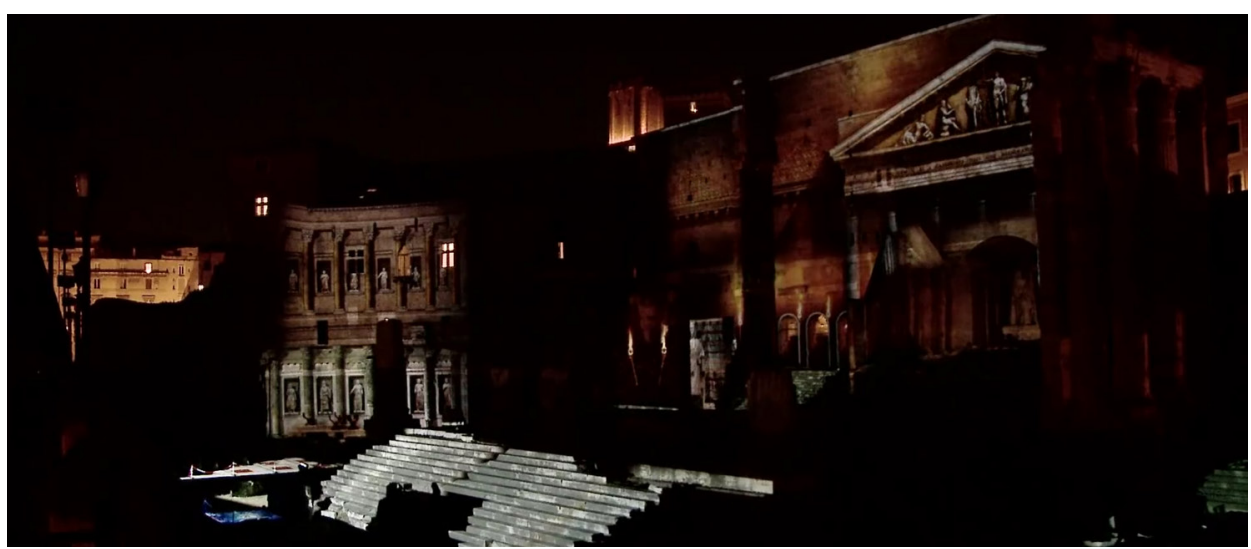

Source: Viaggio nei Fori, n. d.

The Forum initially consisted of the Temple of Mars, two porches that displayed Corinthian style columns, two great symmetrical semicircular platforms, and a bronze chariot with the figure of the emperor in the center of the square (figures 3 and 4). Behind the colonnade at the back wall of the arcades and on the walls of the two Exedra, there were a number of sculptures of historical characters. At the bottom of the portico, on the north side, there was a large room richly decorated with marble, which contained two tables to appeal to a 14-meter-high colossal statue of Augustus.

During the spectacle, the digital surface that is created by the projections on the existing monuments of the Forum introduces the first novel space. This surface visualizes different data: some of these reconstruct the imagery of the site's architecture (figure 5), while others offer a visualization of historical events and personalities. In the first case, the surface is superimposed on the monuments and builds on the existing architectural elements. In the second case, the surface is part of a three-dimensional setting that uses the different depths of the projection perspective to line up with the monument (figure 6). In fact, when considering the technical specificity that follows the installation of the projectors, the distance of 40 $\mathrm{m}$ from the Temple of Mars allows projections all along this dimension as vertical layers. In both cases, the digital surface has no thickness. At certain moments, it follows the outline of the monuments, while at others, it occupies a smaller space, always in relation to the remains. Regarding the design, this surface could be explained as a layer with special characteristics and attributes. As such, it brings to the fore issues of esthetics, and guides the technical requirements for the distribution of screen surfaces. 
Figure 6. Screenshot from the video projections: presentation of data for visual reproduction of reality

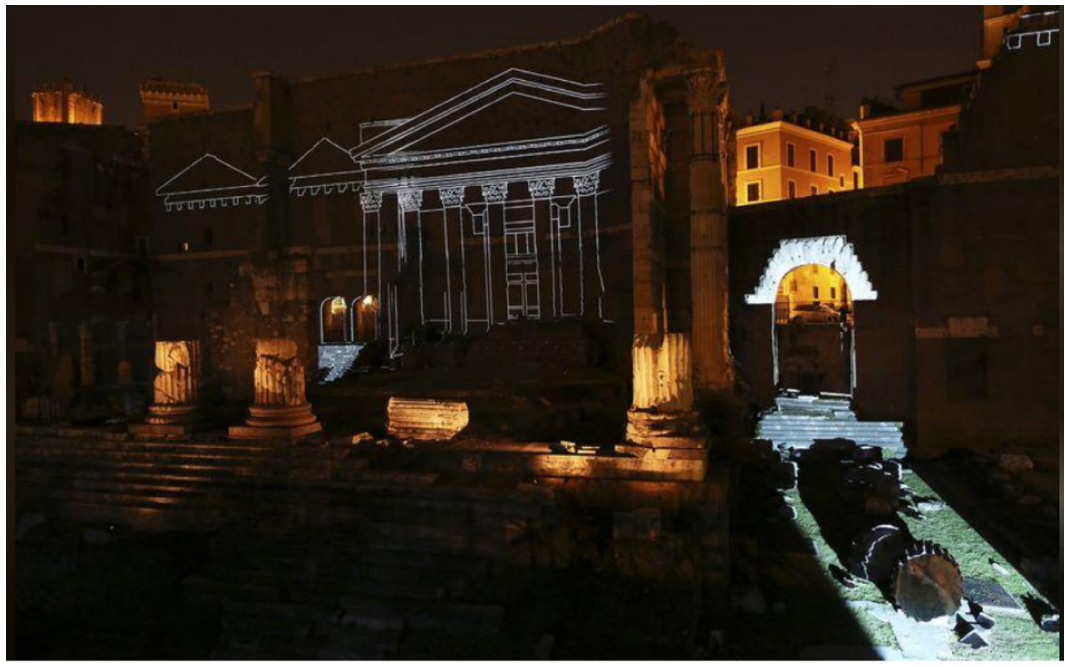

Source: Viaggio nei Fori, n. d.

The digital surface consists of two-dimensional (2D) design elements (lines, shapes, volumes) and reconstructs the facades, architectural details, ornamentation and materials of the building. In its full depiction, the layer reconfigures the design of the portico and accesses of the Temple of Mars in antiquity, medieval times and Renaissance. In most of the cases, the depictions have real dimensions, i.e., a 1/1 scale. In other words, they manage to present elements that are nonexistent today, explain their transformation in time, and transfer the importance they carry in the urban heritage of the site.

All this marks a departure from traditional conservation practices. ${ }^{3}$ It is not physical materiality anymore that allows the complete visualization and analysis of the monumental entity. Rather, this happens through a virtual space projected in real time that depicts the missing parts. Conservation and preservation, in a general framework, represent the concept of evaluating the existing, while restoration is the actual act of intervention once these concepts are commonly accepted.

3 According to a standard definition "architectural conservation constitutes actions and interests that address the repair, restoration, maintenance, and display of historic buildings and sites as well as their associated accoutrements, such as furnishings and fittings" (Stubbs, 2009, p. 21). 
According to Brandi, restoration is "the methodological moment of recognizing a work of art". He also argues that "every work carries with it an esthetical and historical case" (1963, p. 43). The esthetical case refers to the original esthetic decisions of the artist (colors, materials, etc.), while the historical case refers to the way the work has changed in the time that has passed. In this way, for Brandi, restoration is the actual act of intervention, in which an observer (restorer) consciously recognizes an object as a work of art, and not as an object of common use; studies it within its physical, material consistency; and becomes aware of its esthetic and historical values.

When tested in this new hybrid space, awareness in Brandi's Theory forms in the Forum of Augustus as a result of the installation of ICTs, and is constantly faced with the material revival of the missing parts. In fact, the missing parts that are reproduced through ICTs render both the appearance and true substance of the works of art, while respecting their present physical state. In this way, restored parts are not simple replicas of the original ones using similar materials; their esthetic instance and appearance obviously reside through the visual projections that coincide with the materials to be conserved. This can extend to Brandi's Theory and explain how the moment of production of the presented material forms a new concept for contemporary restoration that does not cancel the time that has passed or the creative process of the artist, but allows restorers to transmit its value to the future. As we mentioned before, the projections present memories of the missing cultures, society and traditions that were there before any action of repairing or intervention took place. At the same time, they perform the act of restoring the absent parts in a clear, distinguishing way. These projections have also the power to educate, transmit messages of glory, and alter the emotional charge. In a similar way, the recognition of the artistic value requires the acquisition of data that is based on the knowledge of the current state of the monument and permits the virtual reconstruction of elements that are currently readable or not.

Naturally, the fact that all this happens in a digital manner and, therefore, there is no material intervention to the site is what distinguishes these activities from the science of restoration. However, the physical consistency of the projections (sound, light, measurable spatiality and colors) can be an important way to visualize architectural elements in their original state (figure 7). The materiality of the place and the memories related to the architectural transformations, missing cultures and identity of the place meet in this digital layer. As a result, the surface acquires not only spatial characteristics but also characteristics related to time. Its three-dimensional space is actually flat; that is to say, it obeys the Euclidean geometry. 
Figure 7. Digital restoration of the materiality of the Corinthian columns: recognition of the significance of the project

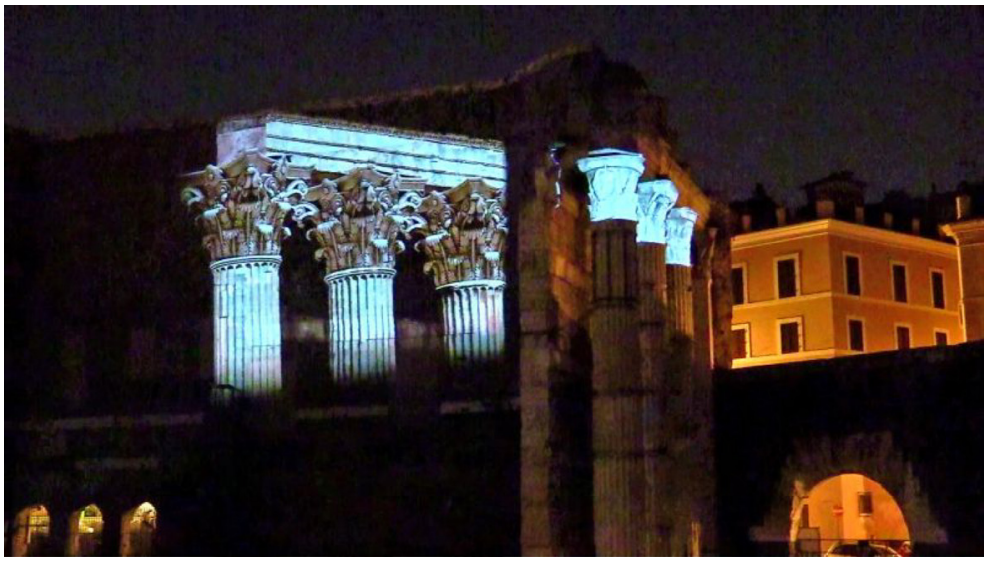

Source: Viaggio nei Fori, n. d.

However, if one imagines that this three-dimensional space wraps the entire archeological site and changes its shape when the parameter of time changes (time of historical representations), then it seems that it should be described as a place where space and timeare intimately connected. Therefore, the data that depicts the projected information specifies its position in space and in time. Combining space and time into space-time leads in this way to a unique way of defining the time and position of each event and its architectural attribute. This marks an important transformation of the way we think of surfaces in geometry. Based on this, we argue that, as it elaborates the issue of time, it might become an important instrument for methodologies of restoration. Specifically, this process entails a methodology to make indistinguishable the digital and the real images through animations, while preserving the monument in its original state (Gabellone, 2009). The result of this activity is the transmission of information to the visitors, offering a wider public an important opportunity to learn. The projections might be of hyper-realistic or simply realistic format. However, in any case, they form a way to augment and decode reality, obviously by recreating it. This activity allows imagining that the projections can act as a sort of distant museum piece at the disposal of the visitors. Locating the visitors in a stable place and quickly changing the images of the projections lead to a perception that they are testimonies of a virtual museum, which help the cognitive processes of memory (Gabellone, 2009). In other words, the use of ICTs for computational reconstructions might 
bring about a spatial dissolution to the concept of a museum and contribute to the work of contemporary restoration, on site or at a distance.

\section{The scale of the immediate surroundings}

Today, the perimeter walls of the Forum's porticos are partly visible. This offers the visitor an idea of a space which is completely permeable and accessible from the Forum of Trajan and the Forum of Nerva. In our times, Via dei Fori Imperiali and Via Alessandrina slice diagonally the original compound, and this makes the regularity of the Fora, the actual dimension of the compound, the spatial boundaries and the scale to be unidentifiable. Most footpaths, entrances and typologies of urban voids (courtyards and galleries) are left to the imagination. Accessibility is not allowed, but Via Alessandrina and the arched opening on the backside of the Forum offer a full view of the area from a place which is three meters higher than the original ancient ground. Several projects for restoration and conservation following the Italian conservation practices/standards (which means that there is a clear distinction between what is new and what is old, and a minimum intervention) are visible on the back wall and on the Corinthian columns. Restoration materials are mainly of different color and substance than the original ones, and they fill certain gaps for structural reasons.

At present, the Forum's connection with the surrounding compounds is also different. While it was originally built as an urban entity attached to others, creating a cluster dedicated to governance, among other purposes, today a visitor cannot easily perceive its rectangular shape and its spatial differentiation. In fact, the demolition of boundaries creates in the visitor the impression of a visual unity of all compounds as far as the Coliseum, with no clear typological differentiation. The remaining massive walls, as well as the position of Via dei Fori Imperiali, visually isolate the area from the dense modern city fabric and, thus, offer the visitor the impression of an enclosed, disconnected urban system. Some openings in the backsides of the Fora and the Coliseum reveal the 18thcentury building typologies with smooth colors that create a sense of familiarity and continuity. The surviving tract of Via Alessandrina appears to be decontextualized from its own previous-centuries original and populous living fabric, and acts more as a catwalk of art, a place where tourists can admire the remaining architectural discoveries in the same way as at a commercial street.

The three-dimensional reproduction of each of the components of the Forum allowed a further understanding of its urban context and the underlying system of relationships with the surrounding monuments, which becomes an important guide for the comprehension of the architectural strategies that have been followed on site (Graham Shane, 2005).

New novel spaces are created for the support and functionality of the spectacle. The first new space regards 
the seating area that hosts the participants. This new collective space has an amphitheater form and orients, therefore, the view of the visitors towards the background massive walls. The concentration of participants in that particular position is very symbolic, since in antiquity it was the place where the Senate gathered. In other words, this space has a dual role: it is a seating, collective space, and metaphorically it acts as a bridge to a moment back in ancient times. This means, firstly, that a collective activity is revived in the same space where it happened in the past. Secondly, it means that this realization might alter the perception visitors have of via Alessandrina, as the street acquires now more a role of a connection to the site and less of a disconnection to it.

The second new space is the place where all projectors and cables are installed. It regards the material/physical use of the existing space, which is transformed into the place that hosts all projectors and relevant technologies. This is not visible to the visitors, but covers a spectrum of digital projections over more than $300 \mathrm{~m}$ in parallel with the monument, the localization of which was decided in relation to the projected objective. The overall space where this hardware is gathered overlaps with the archeological site, hidden to the viewer but nevertheless present. This brings to mind the ways in which the fourth industrial revolution expresses itself in space, blurring the lines between the digital and the physical spheres. Similar to its precedent transformations, its impact is salient, but its materiality not easily perceived. This materiality is part of the physical consistency of the digital surface.

For the passersby of Via dei Fori Imperiali, the street edges with fences create the idea of a porous wall that allows visual connectivity but differentiates completely one side of the street from the other. It seems as if the street had the feature of disconnecting the remaining monumental sites, rather than explaining the links among them. The daily presence of the police, the several measures for the protection of the monument, the seating places and the recreational activities create emotions that enhance public comfort and offer the visitor a pleasant walk in the ancient town. The preserved arched shapes, as well as the visual distraction of the Capitoline Hill, bring about a sense of community and embracement of the area from the surrounding districts.

Age and monumentality are well perceived by the visitors. However, the absence of some of the architectural construction elements make the distinction between a temple, a place of governance, a portico and an agora to be less evident. Some toponyms and buildings - the urban variety of the Alessandrino district -, with functions that sometimes were transferred into the Forum, disappeared leaving the memories of the relocated culture. Stores, taverns, drugstores and churches, everything had been surgically removed for the artificial construction of a new urban landscape, only focused on one road located among the ancient bare and 
isolated ruins. A large amount of the excavated Fora was hidden and a great deal of knowledge was lost. Therefore, from a physical and emotional point of view, the current urban location could be considered as equivocal.

Naturally, walking through the ancient neighborhood is an enlightening experience, and the remaining architectural discoveries in the city center create a rare urban landscape. However, its deep urban heritage is not visually transmitted and requires further research. Considering that one of the main requirements of the memory is its spatialization (Assman, 2008), then it seems that the archeological remains conserved in situ - frozen in an urban 'time slice' - hide several of the site's existential characteristics. This might bring the negative sensation that visitors cannot get the maximum of their experience in the place, and worse, that the information they might collect is bound to interpretations from their personal understanding of the space. At the same time, this leads to a reinforcement of the cultural memory of the visitors, in the context of which "the distinction between myth and history vanishes" (Assman, 2008, p. 113).

\section{Relation to the territory}

Esthetically, the implementation of ICTs changes completely the imagery of the archeological site. It marks the transition of a terrestrial area to a landscape, which is emotionally charged (Viik, 2011). In fact, the projections revived several classical images that refer to the Roman and Greek period. This is manifested through the Romaninspired typefaces used for the names of the emperors, and through the attentive selection of images and frames that transport people to the esthetic reproduction of the monumental art of antiquity. In this way, the esthetic decisions reconcile a memory, an identity, and build in the visitors' consciousness the idea that all data belong to a specific cultural community.

This process creates a new experience that has specific natural, spatial and cultural characteristics. It could be envisioned as a new emerging cluster that more or less mirrors the esthetics and history of the urban fabric (Soja, 1996). The digital component of the projections is a mirror in this sense. It consists of a set of data that describes information from different moments, and offers alternative options on how to work with reality. In other words, this cluster has a dual nature: it is a utopian set of realities that juxtapose on the actual one. Foucault explained the meeting point between utopia and real space in "places that are outside of all places, even though it may be possible to indicate their location in reality" (1986, p. 2). These places, he explained, are somehow "counter sites, a kind of effectively enacted utopia in which the real sites, all the other real sites that can be found within the culture, are simultaneously represented, contested and inverted" (Foucault, 1986, p. 3). The similarity of the hybrid spaces with the heterotypic 
spaces might be an insight for further theoretical constructions on the impact of ICTs on the revival of cultural heritage. In the Forum of Augustus, this is achieved through the use of the light, and through the height and scale of the projections. The result is the construction of an interpretation of the space or else the creation of a group of perceptions, a meaning that applies to the existing space and binds material and immaterial heritage together.

It is worth mentioning that the projections take place in the afternoons when there is low sunlight and the weather allows open-air public activities. The low light intensity, the different illumination and the outburst of colors in the dark act in the human psychology in complex ways, and lead to the creation of new human spatialities (Soja, 1996). As a whole, the esthetic product transforms the original experience and builds a novel imaginary collective landscape.

Other results deriving from the case study are the following: a) the creation of a visual connection among the different places where projections happen simultaneously (Forum of Augustus and Forum of Caesar), b) the transformation of regular visitors into active participants in an emotional experience, and c) the transformation of regular visitors into active participants in a learning experience.

\section{The spillover effect}

It should be noted that the effect of the projections reaches not only the participants of the show but also the ordinary passersby in that area. Since the projection is at the level of the street on Via dei Fori Imperiali, the visual component of the spectacle is visible for everybody, just as the ruins are visible during the day (figure 9). Therefore, the new created hybrid spaces reach not only those paying a ticket to enter but also those being close to the archeological area at the moment of the projections. It seems as if the spectacle spills over to the surrounding street, creating an effect on the city dwellers as well.

In Rome and other European cities, and in the historical centers around the world, the urban cultural heritage becomes quotidian; therefore, the passersby barely notice it anymore. For sure, it is salient for tourists, but for the city dwellers the monuments become simple landmarks in their daily routes (Lynch, 1960).

"An augmented reality experience can situate a learner in a real and meaningful context, yet provide the learner with additional, previously unseen insights" (Klopfer, 2017, p. 53). This is exactly what the ICT projections in the Forum of Augustus cause in the archeological site visitor, but also on the passersby. Thus, they provide the Roman citizens with new insights about these ancient stones that they are so used to see every day, and give them the opportunity to reconsider their meaning.

The new forms of interaction with the walls and stones from the ancient 
past, made available by the superimposition of videos, create a thickness of meaning or, better, unveil the thickness of meaning that the space already contains. For the citizens, there is a renewed emotional connection and a changed perception of space in a city such as Rome, where the urban space is already so charged with signification. In this way, the presence of ICTs on the urban heritage affects the sense of identity of the city and its inhabitants.

Figure 8. Diagrammatic positioning of the relation with the surrounding area, showing the visual range of the projection

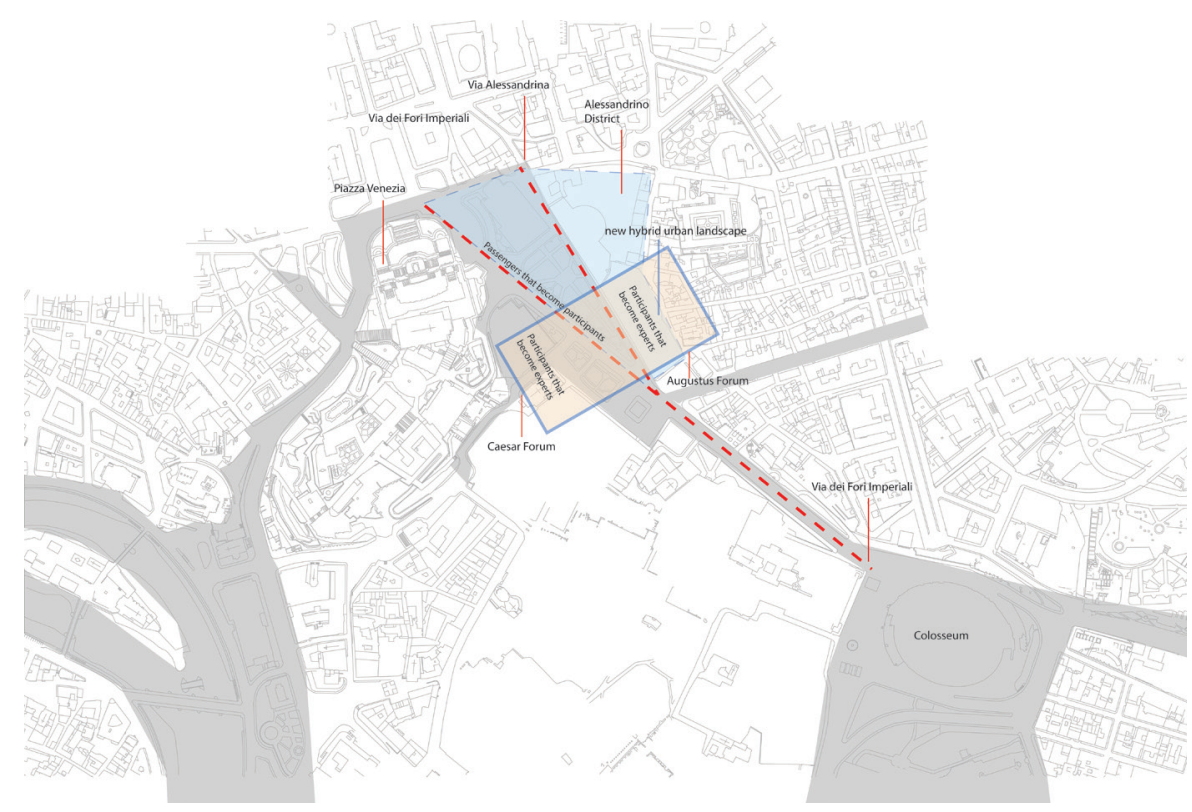

Source: elaborated by the authors

This empowers the argument that projecting information on the monuments generates a better understanding of the area by people and also changes the spatial perspective by this accessibility to new information. As a result, we argue that the experience in the area is influenced by different provocations, and the use of AR alters the impact of the experience. From a physical point of view, it leads to narrations about what this archeological site does in the context of the current city, and what illuminates its role when creating stable objects of memory and identity in their visitors. Emotionally, it manages to show how artifacts of all periods relate to the present and offer a different experience to 
the user. There is the social experience manifested in the synthesis of knowledge about the social reality of the space: emotions for understanding, learning, being safe, belonging and admiring.

\section{Conclusions}

We have proposed a contribution to the field by analyzing this novel case study from the combined perspectives of architecture and communication. The new hybrid spaces created by projections on the cultural heritage bring different experiences of the city that could have philosophical implications (e.g. the revival of the agora's nature through the citizens that listen to the stories of their forefathers), and also implications for daily social practices.

The urban space of the fourth industrial revolution has great significance, because it refers to the past mixed with current technology. The projections on the Imperial Fora in Rome apply a digital layer on rough, irregular surfaces, creating smart spaces that celebrate the richness of the local and the unique, in the conformation of a smart district. They revive and reveal to the lay observer the thickness of meaning which is present in the monuments that only experts were able to see with bare eyes before. Lastly, they create hybrid spaces combining the digital with the physical and, in doing so, they make the Forum to be a place once again worthy of observation, not only for visitors, but also for the locals that pass by in their daily activities, thus contributing to a renewed sense of identity for the inhabitants of the eternal city.

The phenomenon analyzed here will be more common in cities of all continents, driven by local stakeholders in the districts with a vocation towards tourism. A very similar example to our case study was launched in late 2011 for the Purana Qila in Delhi, India (Cook, 2018), while many more examples of Augmented Reality are emerging in museums all around the world.

Further research is needed concerning Augmented and Virtual Reality experiences in heritage sites because this application of ICTs for the revival of monuments, architectural remains and public buildings has implications for the understanding of the past and for the sense of identity of local cultures. It is also an instance of the pervasiveness that data will reach in the fourth industrial revolution, seeping into the crevices of our day-to-day life. 


\section{References}

Acea. (2017). Smart City a Roma: Progetti per la Mobilità Sostenibile. Retrieved from https:// romamobilita.it/sites/default/files/pdf/mobilityweek2017/PPT_Acea_DEF.pdf

Assman, J. (2008). Communicative and Cultural Memory. In A. Erll \& A. Nünning (Eds.), Cultural Memory Studies: An International and Interdisciplinary Handbook (pp. 109-118). Berlin, Germany: De Gruyter.

Barth, L. (2012). Workspace urbanism: the architecture of transformation/rethinking the civic landscape. INTA TALLIN Conference.

Bimber, O., \& Raskar, R. (2005). Spatial Augmented Reality: A Modern Approach to Augmented Reality. In Proceedings of Annual Conference on Computer Graphics and Interactive Techniques - SIGGRAPH'05. New York, NY: ACM Press.

Brandi, C. (1963). Teoria del Restauro. Roma, Italy: Edizioni di Storia e Letteratura.

Cook, S. (2018). 7 Sound and Light Shows in India that You Shouldn't Miss. TripSavvy [website]. Retrieved from https://www.tripsavvy.com/ must-see-sound-and-light-shows-1539796

De la Fuente Prieto, J., Castaño Perea, E., \& Labrador Arroyo, F. (2017). Augmented reality in architecture: Rebuilding archeological heritage. The International Archives of the Photogrammetry, Remote Sensing and Spatial Information Sciences, XLII(2), 1-3.

EY. (2016). Italia Smart: Rapporto Smart City Index 2016. Retrieved from http:// www.comune.bologna.it/iperbole/piancont/archivionov/tabelle_grafici/ EYsmartindex/2016-EY-smart-city-index.pdf

Foucault, M. (1986). Of Other Spaces. (Trans. J. Miskowiec). Diacritics, 16(1), $22-27$.

Gabellone, F. (2009). Ancient contexts and virtual reality: From reconstructive study to the construction of knowledge models. Journal of Cultural Heritage, (10), 112-117.

Geropanta, V., \& Cornelio-Marí, E. M. (2014). Defining smart space: Scales of interaction between architecture and social practices. Comunicazionepuntodoc, 10, 165-181.

Giffinger, R., Kramar, H., Haindlmaier, G., \& Strohmayer, F. (2015). The smart city model. Retrieved from http://www.smart-cities.eu/?cid=2\&ver=4

Graham Shane, D. (2005). Recombinant Urbanism-Conceptual Modelling in Architecture, Urban Design, and City Theory. London, UK: Wiley Academy.

Hedrick-Wong, Y., \& Choong, D. (2017). Global Destination Cities Index by Mastercard. Retrieved from https://newsroom.mastercard.com/wp-content/ uploads/2016/09/FINAL-Global-Destination-Cities-Index-Report.pdf

Klopfer, E. (2017). Augmented Reality. In K. Peppler (Ed.). The SAGE Encyclopedia of Out-of-School Learning. Thousand Oaks, CA: SAGE Publications, Inc.

Komninos, N. (2014). The Age of Intelligent Cities: Smart Environments and Innovation-forAll Strategies. London, UK: Routledge. 
Lynch, K. (1960). The Image of the City. Cambridge, MA: MIT Press.

May, T., Perry, B., Le Galès, P., Sassen, S., \& Savage, M. (2005). The Future of Urban Sociology. Sociology, (39), 343.

Parthenios, P., Peteinarelis, A., Lousa, S., \& Efraimidou, N. (2015). Three modes of a monument's 3D virtual reconstruction the case of Giali Tzamissi in Chania, Crete, Digital Heritage, (1), 75-78.

Ronchi, A. M. (2009). eCulture, Cultural Content in the Digital Age. Berlin: Springer.

Schwab, K. (2016). The Fourth Industrial Revolution: what it means, how to respond. World Economic Forum [website]. Retrieved from https://www.weforum.org/ agenda/2016/01/the-fourth-industrial-revolution-what-it-means-and-how-torespond/

Sistemi Integrati. (2014). Il Foro ai tempi di Augusto: ricostruzione virtuale con 33 videoproiettori. Retrieved from https:/www.panasonic.com/it/corporate/news/ articles/il-foro-ai-tempi-di-augusto--ricostruzione-virtuale-con-panasoni.html

Soja, E. (1996). Thirdspace: Journeys to Los Angeles and Other Real-and-Imagined Places. Cambridge: Blackwell.

Viaggio nei Fori. (n. d.). [Image file]. Retrieved from http://www.viaggioneifori.it/en/

Viik, T. (2011). Human spatiality: a cultural phenomenology of landscapes and places. Problemos, (79), 103-114. Retrieved from http://www.journals.vu.lt/problemos/ article/viewFile/1323/732 